\title{
COVID-19 and its Repercussions on Vascular and Abdominal Medical Emergency Scenario. Interinstitutional, Multidisciplinary Approach
}

Carlos Adrián Torrejón-Hernández ${ }^{1, *}$, Héctor Bizueto-Rosas², Moisés Alejandro Perdomo Galván ${ }^{3}$, Ana Karen Trujillo-Araujo ${ }^{3}$, Francisco Jazir Castro Carrillo ${ }^{3}$, Alfonso Cossío-Zazueta ${ }^{4}$, Raúl Beder Caltenco-Solís ${ }^{1}$, Camilo Andrés Echeverry-Fernández ${ }^{1}$, Jaime Roberto Magaña-Salcedo ${ }^{1}$, Jesús Nicolás Hidalgo-Delgado ${ }^{1}$, Jesús Eduardo Prior-Rosas ${ }^{1}$, Mayerlin Calvache-Muñoz ${ }^{1}$, Noelly Noemí Bizueto-Blancas ${ }^{5}$, Jesús García-Chávez², José Alberto Valdés-Serafín ${ }^{2}$, and Noemí Antonia Hernández-Pérez ${ }^{6}$

${ }^{1}$ General Surgery Resident, Dario Fernandez Fierro General Hospital, Institute for Social Security and Services for State Workers (ISSSTE), Mexico City, Mexico

${ }^{2}$ General Surgeon, Dario Fernandez Fierro General Hospital, ISSSTE, Mexico City, Mexico

${ }^{3}$ Angiology Resident, Dr. Antontio Fraga Mouret High Specialty Hospital, Mexican Social Security Institute (IMSS), Mexico City, Mexico

${ }^{4}$ Chief of Angiology Service, Dr. Antonio Fraga Mouret High Specialty Hospital, IMSS, Mexico City, Mexico

${ }^{5}$ Medicine Student, Saint Luke School of Medicine, Mexico City, Mexico

${ }^{6}$ Family and Laboral Medic, Mexico City, Mexico

*Corresponding authors: Carlos Adrián Torrejón Hernández, General Surgery Resident, Dario Fernandez Fierro General Hospital, Institute for Social Security and Services for State Workers (ISSSTE), Mexico City, Mexico; E-mail: titos962@hotmail.com

Received: 10 Apr, 2021 | Accepted: 14 Jun, 2021 | Published: 08 Jul, 2021

Citation: Torrejón-Hernández CA, Bizueto-Rosas H, Galván MAP, Trujillo-Araujo AK, Carrillo FJC, et al. (2021) COVID 19 and its Repercussions on Vascular and Abdominal Medical Emergency Scenario. Interinstitutional, Multidisciplinary Approach. J Surg Open Access 7(4): dx.doi. org/10.16966/2470-0991.243

Copyright: (c) 2021 Torrejón-Hernández CA, et al. This is an open-access article distributed under the terms of the Creative Commons Attribution License, which permits unrestricted use, distribution, and reproduction in any medium, provided the original author and source are credited.

Abstract

Objective: To identify the causes related to a rise in morbidity and mortality due to COVID in the most frequent events of acute abdomen and vascular disease.

Introduction: SARS-CoV-2 disease is a syndrome which includes respiratory, digestive, hepatic, and cardiovascular and nervous systems. $20 \%$ of positive cases present gastrointestinal symptoms whereas vascular manifestations appear up to $15 \%$.

We are facing a new scenario, where well known practices involving the most common abdominal and/or vascular diseases approaches must change remarking a thorough anamnesis on all medical attention levels. Uncomplicated surgical diseases have increased morbidity and mortality rates due to fear and disinformation in both, patients and medical staff.

Methods: An ambispective, observational, descriptive, multicentric and multidisciplinary study was carried out with the most frequent abdominal and vascular pathologies, since pandemic establishment. Identifying delaying factors in surgical management, evaluating predominant symptoms and postoperative complications.

Results: Fifty-seven patients, 22 form vascular surgery service (Group I) and 35 from general surgery (Group II) were included.

Group I: Average age 60.7 years; 16 men, 6 women; PCR positive 55\%; 7 deaths, 18\% PCR positives; 8 with delayed treatment due to administrative issues; without apparent cause: embolism to mesenteric root, aorta, vena cava, pulmonary artery, lower limbs, coronary and carotid vessels. Diabetics $35 \%$, hypertensive disease $30 \%$.

Group II: 20 men, 15 women; average age 62.5 years; 12 deaths, 7 men, 5 women; diabetics and hypertensive $30 \% ; 3$ hemicolectomies due to acute appendicitis; 2 cholecystectomies with acute abdomen management. 1 intestinal resection due to incarcerated hernia with fistulae. 4 amputations.

Conclusion: We have a long road ahead to deal with this new pandemic scenario; medicine teaching should focus on prophylaxis and a preventive approach instead only therapeutic, simulating real life scenarios to be better prepared.

Keywords: COVID-19; Acute abdomen; Arterial insufficiency; Complications

Abbreviations: M: Patient's fear to medical environment due to the pandemic; DE: Wrong diagnostic approach which lead to sing in patients into COVID areas; MPMP: Medical staff fear to treat COVID-19 patients; PPST: Prioritizing COVID-19 diagnosis over other life-threatening illness the patient presented; SARS-CoV-2: Type 2 Coronavirus Severe Acute Respiratory Syndrome; COVID: Corona Virus Disease; ACE2: Angiotensin Converting Enzyme 2; MERS: Middle East Respiratory Syndrome 


\section{Introduction}

World Health Organization (WHO) baptized the new disease as "disease by coronavirus 2019" (COVID-19) and the taxonomy virus committee as SARS-CoV-2 (Severe Acute Respiratory Syndrome) The disease by SARS-CoV-2 virus is a constellation of symptoms with manifestations on the respiratory, gastrointestinal, hepatic, cardiovascular and nervous systems. With more than two hundred thousand deaths in Mexico [1,2].

We are upon a new health scenario created by the pandemic. Traditional view around acute abdomen approach should be changed, with a remark on a thorough medical history in all attention levels. Due to lack of information and fear, there has been a delay on optimal care windows in surgical cases. Leading to the presentation of advance and more complicated cases, hence, rising morbidity and mortality rates.

Up to date, Dr. Felipe Martinez Lomakin from Andres Bello University, has reported the infection caused by the new coronavirus strains, as an acute respiratory distress syndrome; leading with a massive inflammatory response due to immune reply against the virus.

COVID-19 is a single chained enveloped ARN. The complete sequence of its genome has classified it on the Betacoronavirus genre, and Coronavirinae subfamily. A similar genome to bat and pangolin coronavirus has suggested them as the virus main and intermediate hosts in nature $[3,4]$. It seems to interact through the trimeric $S$ glycoprotein with the Angiotensin-Converting Enzyme 2 (ACE2) with a structural rearrange which allows viral fusion to human host cells [4].

The virus has been found in nostrils, saliva, sputum, throat, blood, bile and feces. It has also been reported within respiratory and gastrointestinal tract cells. There are many hypothesis about transmission mechanisms [3].

The coronavirus $S$ protein acts like a key in the cell's receptor allowing it to enter its host and start replication. The more receptor a cell has, the more likely it is to generate infection.

There have been hypothesis about why the male population is more vulnerable to COVID-19. Recent studies reveal that higher blood levels of ACE2 could increase COVID-19 activity the host's cells [5].

The virus adheres to the alveolar epithelial cells through its spike surface protein which engages to the ACE2 over the cell membrane [5]. ACE2 works as a receptor after the spike protein activation by the transmembrane protease serine [2]. Once inside the cell, the virus presents fast replication leading to a high viral load $[5,6]$.

The disease has a higher morbidity and mortality in advanced age and patients with comorbidities such as diabetes, hypertension and vascular disease.

Severe cases have shown an elevated cytokine release and activation characterized by higher levels of IL-1, IL-6, tumor necrosis factor, and other minor cytokines; this activity creates cellular reaction on endothelium, platelets, monocytes and other tissues. A rise on thrombin generation and a decrease on anticoagulant factor leads to a prothrombotic state.

Coagulopathy associated with COVID-19 is related to severe disease and increased mortality [7].

Complement activation contributes to pulmonary damage and other organic failures [8]. Microvascular thrombosis could be specific to COVID-19 by its affinity for ACE2 in respiratory and vascular tissue. Time and elevated D Dimer counted in day 10-14 of patients who did not survive. It has been reported that a high D-Dimer level $(>0.5 \mathrm{mcg} / \mathrm{ml})$ is associated to a higher death risk (59.6\%). An initial rise in fibrinogen levels have also been reported with a subsequent decrease in patients with high mortality $[8,9]$.

COVID-19 could induce arterial and venous thrombosis, with a higher incidence on severe illness [9]. Arterial thrombosis is occasionally observed due to the higher velocity and pressure compared to the venous system. Cases with high mortality sequels have reported myocardial infarction or intestinal ischemia. Acute thrombosis of extremities requiring surgical treatment, have also been detected $[10,11]$.

Some other reports state that $31 \%$ of critical SARS COV 2 patients present a vascular complication, with pulmonary thrombosis in $81 \%$ of them [9].

Up to $10 \%$ COVID-19 positive patients begin their illness with digestive symptoms such as diarrhea, nausea and abdominal pain. Abdominal pain could be confused with pancreatitis or abdominal sepsis etiologies. $80 \%$ of the patient's present lymphopenia and mild thrombocytopenia in worst prognostic scenarios; reporting also a non-specific increase in $\mathrm{D}$ dimer. Procalciton in has been reported to increase in up to $5 \%$ of the cases, whereas $\mathrm{C}$ reactive protein has a direct relationship with prognosis and disease severity.

Mild to moderate abdominal pain is probably related to the diminished oxygen concentration in blood which could lead to intestinal ischemia, digestive bleeding, pain, ileum, pancreatitis, and other non-specific manifestations [10].

Moreover, other reports have shown alleged COVID related appendicitis, treated with medical management and confirmed with virus detection on feces.

The mortality overall index has been reported in $24.5 \%$; where thrombotic events (43.2\%) were in the higher category: pulmonary embolism in 3.2\%, arterial thrombosis in $11.1 \%$ (1.6\% ischemic stroke, $8.9 \% \mathrm{MI}$, and $1 \%$ systemic thromboembolic event). With a consequent rise on ICU patients with $29.4 \%$ (venous 13.6, arterial 18.6\%) [12]. Some other patients got worse very fast (within minutes).

Approaching strategies are different among institutions and may probably change as long as we learn more about this disease.

In ICU units of the Cleveland Clinics, DVT was detected on 25-30\% while Cui et al reported a $25 \%$ incidence in sever COVID pneumonia cases [13]. Maatman reported up to a $25 \%$ of prophylaxis failure against DVT $[14,15]$.

Other key factors for thrombosis presentation are a sedentary lifestyle, age above 70 years, overweight, oncologic disease and coagulopathies.

The most frequent vascular manifestation on COVID-19 patients is deep vein thrombosis. Pathologic reports of COVID-19 patients have found disseminated clots and micro hemorrhages mainly on the respiratory system [14].

\section{Methods}

An ambispective, observational, descriptive study was carried out since the official COVID-19 pandemic establishment with patients treated in the angiology and general surgery units in the hospitals Dr. Antonio Fraga Mouret (IMSS) and Dr. Dario Fernandez Fierro (ISSSTE). 
Medical attention delaying causes were assorted among most frequent vascular and abdominal consultation diagnosis. These causes were divided in: Patient discomfort/fear to assist a medical consultation (M), misdiagnosis that classified a patient into a COVID area (DE), Medical personnel discomfort/fear to do diagnostic work up (MPMP), and focusing on COVID-19 diagnosis disregarding main pathology for which the patient needed medical attention (PPST).

Predominant symptoms and complications were evaluated in each pathology.

\section{Results}

A total of 57 patients were included, 22 of vascular etiology (Group 1, Table 1) and 35 from surgical etiology (Group 2, Table 2).

In group 1, 16 men (average age 60.7, ranging from 16 to 87 years) and 6 women (average age 56.6, ranging from 52 to 67 years) (Table 3) with 54.5\% COVID-19-positive PCR. 7 deaths (6 men and 1 woman), 4 of them COVID19-positive.

During group 1 analysis, 8 patients were admitted with COVID-19 from which PCR test confirmed 7 of them. 3 patients presented SARS COV 2 so their vascular diagnosis came in second term. 8 had a delayed attention to COVID-19 symptoms, by administrative reasons. One patient received delayed medical attention due to fear/discomfort of going to a hospital. Initial vascular diagnosis was performed in 17 patients: 2 mesenteric thrombosis, 2 aortic and vena cava thrombosis without apparent risk factors. One death without risk factors, neither confirmed COVID 19 diagnosis (Image 1). 2 MI, one pulmonary embolism, one common carotid thrombosis, and 2 DVT.

8 patients presented lower extremity advanced arterial disease, 3 were amputated and 5 surgically explored. Later reporting 100\% mortality due to systemic complications. 4 patients presented with arterial disease in upper extremity from which 2 were amputated and 2 treated with anticoagulation with good recovery.

Most frequent comorbidities were: Type 2 Diabetes Mellitus (34.7\%), Essential hypertension (30.4\%), type 2 diabetes and hypertension (27.1\%), obesity (1\%). Associated risk factors in deceased were type 2 diabetes (13\%), diabetes and hypertension (8.6\%), liver failure (4.5\%), with hematologic comorbidities (4.5\%); any comorbid disease (21.7\%).

Group 2 analysis included 35 patients, 20 males and 15 females ranging from 35 to 88 years. Reporting 7 male and 5 female deceased, $45.5 \%$ between 40 and 59 years. $30 \%$ of the mortality rate presented type 2 diabetes and hypertension while $60 \%$ had essential hypertension.

Five patients were diagnosed with COVID-19 in group 1 . Whereas in group 2; 21 patients resulted positive, 5 unspecified, 8 negative and one was pending to this article's publication.

Seven appendectomies were performed, none diagnosed at the beginning; two required hemicolectomies and ileo-transverse anastomosis, three were managed with primary closure, and one presented enteroatmospheric fistula which later required ileostomy

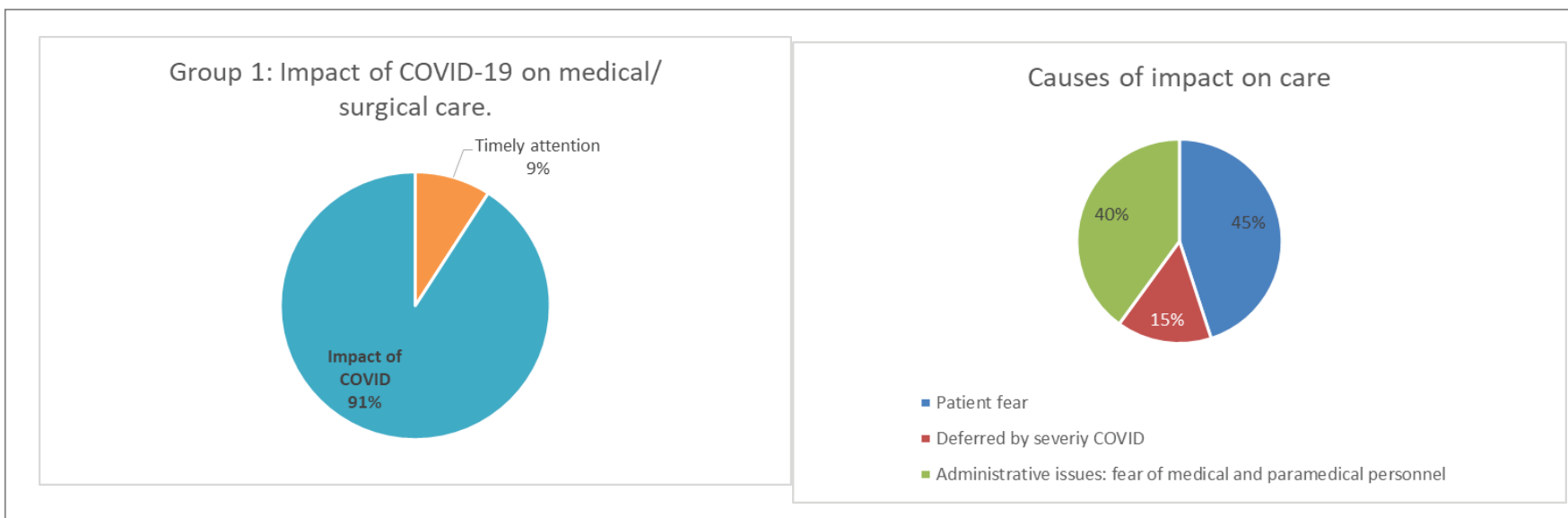

Group 1: Percentage of patients who were seen on time and of those who were seen late for various causes secondary to the COVID pandemic.
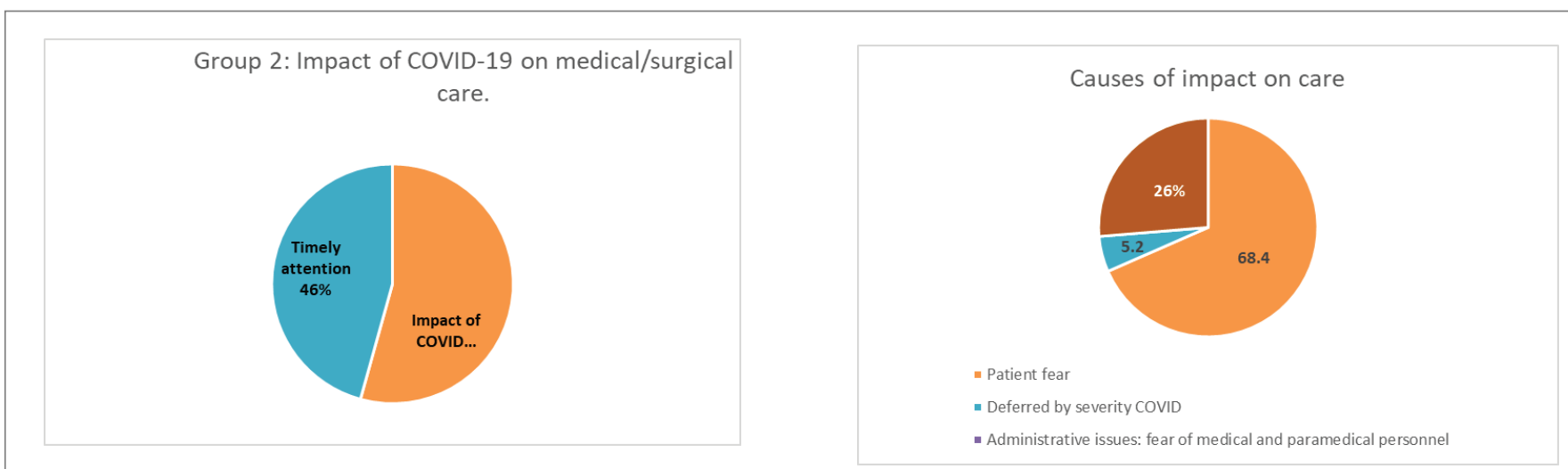

Group 2: Percentage of patients who were seen on time and of those who were seen late for various causes secondary to the COVID pandemic. 
Table 1: COVID 19 effects on medical/surgical treatment in group 1.

\begin{tabular}{|l|c|c|}
\hline \multicolumn{1}{|c|}{ Total } & $\mathbf{2 2}$ & $\mathbf{2 2}$ \\
\hline Covid-19 related & 20 & 20 \\
\hline Fear & 1 & 9 \\
\hline Deferred by COVID severity & 3 & 3 \\
\hline Administrative related delay & & 8 \\
\hline $\begin{array}{l}\text { Adequate approach } \\
\text { and treatment }\end{array}$ & 2 & 2 \\
\hline COVID 19 related delay & 20 & 20 \\
\hline Patient's COVID concern delay & & 9 \\
\hline Deferred by severity COVID & & 3 \\
\hline $\begin{array}{l}\text { Administrative issues: fear of medical and } \\
\text { paramedical personnel }\end{array}$ & & 8 \\
\hline
\end{tabular}

Table 2: Group 2 COVID 19 effects on medical/surgical treatment in group 1.

\begin{tabular}{|l|c|c|c|}
\hline \multicolumn{1}{|c|}{ Total } & & 35 & \\
\hline COVID related delay & 19 & 19 & 100 \\
\hline Patient's COVID concerns delay & 16 & 13 & 68.4 \\
\hline $\begin{array}{l}\text { Deferred by COVID } \\
\text { severity }\end{array}$ & & 1 & 5.2 \\
\hline Administrative related delay & & 5 & 26.3 \\
\hline $\begin{array}{l}\text { Adequate approach } \\
\text { and treatment }\end{array}$ & 16 & \\
\hline
\end{tabular}

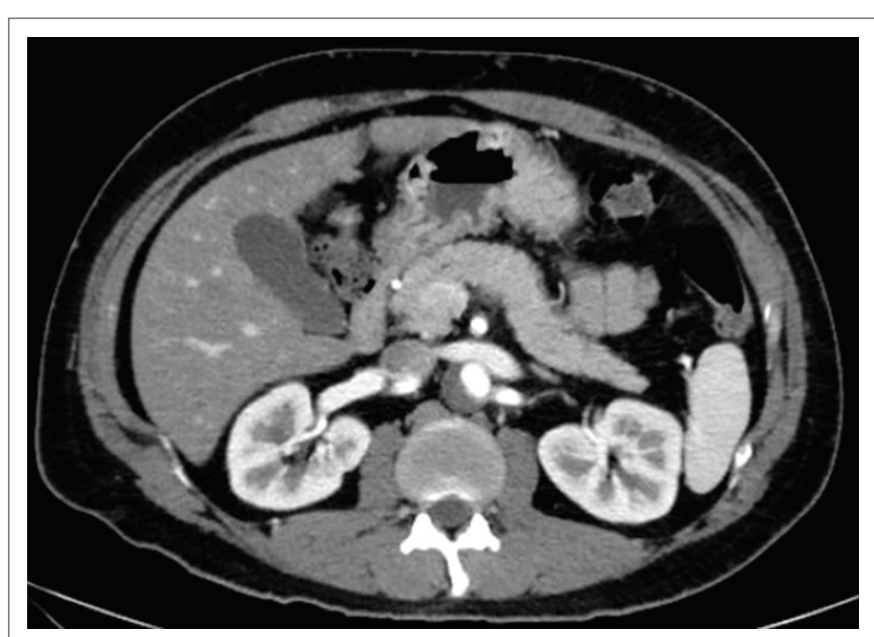

Image 1: Angiotomography, 40-year-old male with aortic cava thrombosis. Without risk factors. Probable COVID 19, deceased.

and open abdomen treatment. Five patients were self-medicated in order to avoid hospitals due to the pandemic while 2 presented initial diagnosis of COVID-19 taking abdominal symptoms to secondary term.

Two patients with gallbladder etiology were admitted for delayed treatment due to concerns about the pandemic, being later diagnosed with COVID-19. One of them required an exploratory laparotomy due to biliary peritonitis, and died later due to septic complication. The second patient presented an infected gallbladder which was removed laparoscopically.

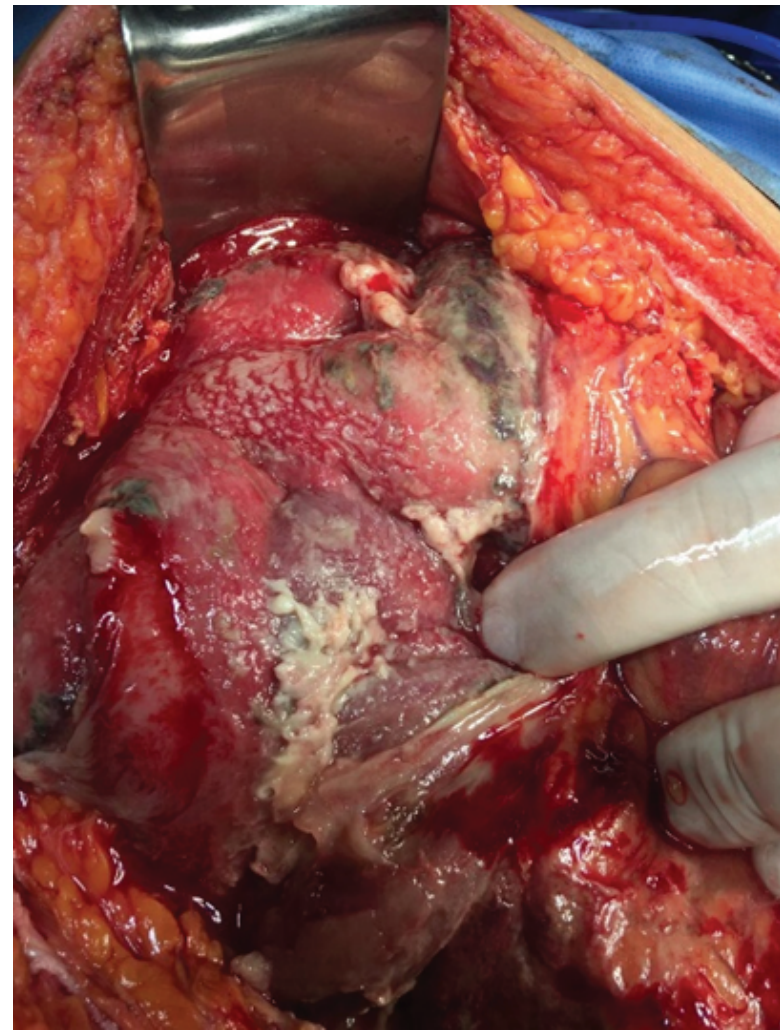

Image 2: Incarcerated hernia with intestinal perforation.

Four acute perforations; 3 subjects showed intestinal perforation and two of them were initially treated for severe COVID-19 symptoms. One patient reported a perforated gastric ulcer who in spite of marked abdominal symptoms, came to delayed treatment due to pandemic concerns and died during hospital stay.

A patient with incarcerated hernia presented advanced stages of necrosis and perforation due to pandemic concerns, undergoing intestinal resection and anastomosis. Later, anenteroatmospheric fistula was observed and a second intervention and ileostomy was required (Image 2).

\section{Discussion}

Thrombosis has been reported as one of the main complications in COVID-19 patients.

The patients have been stigmatized due to the lack of information available.

Even when the main COVID-19 symptoms focus on respiratory system; a fifth of the patients present gastrointestinal and/or vascular manifestations.

Surgical acute abdomen requires a fast and accurate approach which was delayed because health system is focused on the pandemic.

Vascular thrombosis cases, representing a functional risk, require an immediate response which was also delayed for pandemic concern.

\section{Appendicitis mortality}

Present mortality: the probability of dying due to a non-complicated appendicitis is lower than $0.1 \%$ [16]. 
Table 3: Risk Factors, Affected Sites, and Treatment.

\begin{tabular}{|c|c|c|c|c|c|c|}
\hline Age & Average & Most affected age group & & & Range & Total \\
\hline Male & 60.7 & $50-69$ & & & $16-87$ & 16 \\
\hline Female & 56.6 & $52-67$ & & & $20-82$ & 6 \\
\hline HAS & & & & & & 0.3 \\
\hline DM2 & & & & & & $34-7 \%$ \\
\hline Obesity & & & & & & 0.7 \\
\hline Smoking & & & & & & 0.3 \\
\hline Positive PCR & & & & & & 0.55 \\
\hline \multicolumn{7}{|l|}{ Risk Factors } \\
\hline None & & & & & & $7(31.8 \%)$ \\
\hline less than 2 & & & & & & 0.35 \\
\hline 3 or more & & & & & & 0.3 \\
\hline \multicolumn{7}{|l|}{ Sites } \\
\hline Arterial Msls & & & & & & 17 \\
\hline Venous Msls & & & & & & 2 \\
\hline Carotid & & & & & & 1 \\
\hline Coronary Disease & & & & & & 2 \\
\hline Pulmonar & & & & & & 1 \\
\hline Abdomen & & & & & & 2 \\
\hline \multicolumn{7}{|c|}{ Sings/symptoms of Covid } \\
\hline & & & & & & 8 \\
\hline \multicolumn{7}{|c|}{ Arterial and Venous Thrombosis } \\
\hline Cava/aorta & & & & & & 2 \\
\hline \multicolumn{7}{|l|}{ Treatment } \\
\hline \multicolumn{7}{|c|}{ Delayed COVID severity (PSST) } \\
\hline & & & & & & 3 \\
\hline \multicolumn{7}{|c|}{ Administrative delay (DE/MPMP) } \\
\hline & & & & & & 8 \\
\hline \multicolumn{7}{|l|}{ Fear related delay (M) } \\
\hline & & & & & & 9 \\
\hline \multirow[t]{2}{*}{ Amputations } & Early & Delayed & deferred & Expectant & & Mortality \\
\hline & & 3 & & & & 3 \\
\hline Arterial exploration & 5 & & & & & 5 \\
\hline \multicolumn{7}{|l|}{ Arterial disease } \\
\hline Upper limbs & 2 & & & 2 & & 0 \\
\hline
\end{tabular}

Appendicitis could be a severe disease if it is not resolved in early stages, presenting a morbidity of $37 \%$ and mortality of $1 \%$ [17].

Mortality in open appendectomy is reported between 0.3 and $11 \%$ [18].

Perforation rate in delayed treatment of appendicitis is reported about $34 \%$ with a mortality of $0.5 \%$ [19].

\section{Mortality in hemicolectomy secondary to complicated appendicitis}

Approximately $1.7 \%$ of complicated appendicitis requires right hemicolectomy with primary anastomosis. Presenting complications in $70 \%$ of the cases, with a mortality of $5 \%$ [20].

\section{Gallbladder resection mortality}

In an emergency scenario, death rate in cholecystectomy for acute gallbladder disease is reported between 0.8 to $2 \%$ [21]. Biliary peritonitis is a rare complication reported in $11 \%$ of acute disease with a $70 \%$ mortality rate [22].

\section{Mortality in embolectomy}

Embolectomy death rate ranges from 20 to $25 \%$ ending in amputation in up to $20 \%$ of the cases [23]. Other authors as PérezPrada KJ, et al. Torres have reported late embolectomy (10 to 14 hours after clotting event) with an amputation rate of $32.3 \%$ and a $10 \%$ mortality rate; the Sierra Juarez group reported a $16 \%$ amputation rate 
with only $6 \%$ mortality rates. They demonstrated an average time of 12 days between clotting event and treatment [24,25].

Moreover, pneumonia has been reported as the main post amputation complication [ 30 to $40 \%$ ], with a $20 \%$ mortality rate. In patients with arterial disease along with COVID-19 symptoms and positive test, the mortality rate was $87.5 \%$.

Some of the socio-demographic variables to consider were

1. Education
2. A relatively young and productive country with a main working activity outside an office environment

3. Concurrence of other pandemics, such as obesity and diabetes

4. Smoking rate is among the highest worldwide

COVID-19 most affected population ranged between 50 and 60 years in group 1, with average age: 60.7 mean: 54, average age at death: 52.1 years (Graph 1) similar to national statistics (Graph 2). Whereas, in group 2 the average age was 59 years with a mean age

Table 4: Risk factors, affected sites, and treatment.

\begin{tabular}{|c|c|c|c|c|c|c|}
\hline Age & Average & Most affected age group & & & Range & Total \\
\hline Male & 62.5 & $70-88$ & & & $35-88$ & 20 \\
\hline Female & 45.4 & $40-59$ & & & $22-82$ & 15 \\
\hline HAS & & & & & & 0.6 \\
\hline DM2 & & & & & & 0.3 \\
\hline Obesity & & & & & & 0.7 \\
\hline Smoking & & & & & & 0.6 \\
\hline Positive PCR & & & & & & 0.6 \\
\hline \multicolumn{7}{|l|}{ Risk Factors } \\
\hline None & & & & & & 9 \\
\hline less than 2 & & & & & & 2 \\
\hline 3 or more & & & & & & 23 \\
\hline \multicolumn{7}{|l|}{ Sites } \\
\hline Arterial Msls & & & & & & 6 \\
\hline Venous Msls & & & & & & 1 \\
\hline \multicolumn{7}{|l|}{ Carotid } \\
\hline \multicolumn{7}{|l|}{ Coronary Disease } \\
\hline \multicolumn{7}{|l|}{ Pulmonar } \\
\hline \multicolumn{7}{|l|}{ Abdomen } \\
\hline \multicolumn{7}{|l|}{ Sings/symptoms of Covid } \\
\hline \multicolumn{7}{|l|}{ Arterial and Venous Thrombosis } \\
\hline Cava/aorta & & & & & & 2 \\
\hline \multicolumn{7}{|l|}{ Treatment } \\
\hline Delayed COVID severity (PSST) & & & & & & 1 \\
\hline Administrative delay (DE/MPMP) & & & & & & 5 \\
\hline Fear related delay (M) & & & & & & 13 \\
\hline Procedure & Early & Delayed & Deferred & Expectant & & Mortalilty \\
\hline Amputations & 2 & 4 & & & & 1 \\
\hline Appendectomy & & 7 & & & & \\
\hline Hemicolectomy & & 2 & & & & \\
\hline Cholecistectomy & & 2 & & & & \\
\hline $\begin{array}{l}\text { Cholecistectomy+additional } \\
\text { procedures }\end{array}$ & & 1 & & & & 1 \\
\hline Laparotomy & & 4 & & & & \\
\hline \multicolumn{7}{|l|}{ Intestinal Tract Perforation } \\
\hline Intestinal & & 3 & & & & \\
\hline Gastric & & 1 & & & & 1 \\
\hline Incarcerated hernia & & 1 & & & & \\
\hline
\end{tabular}




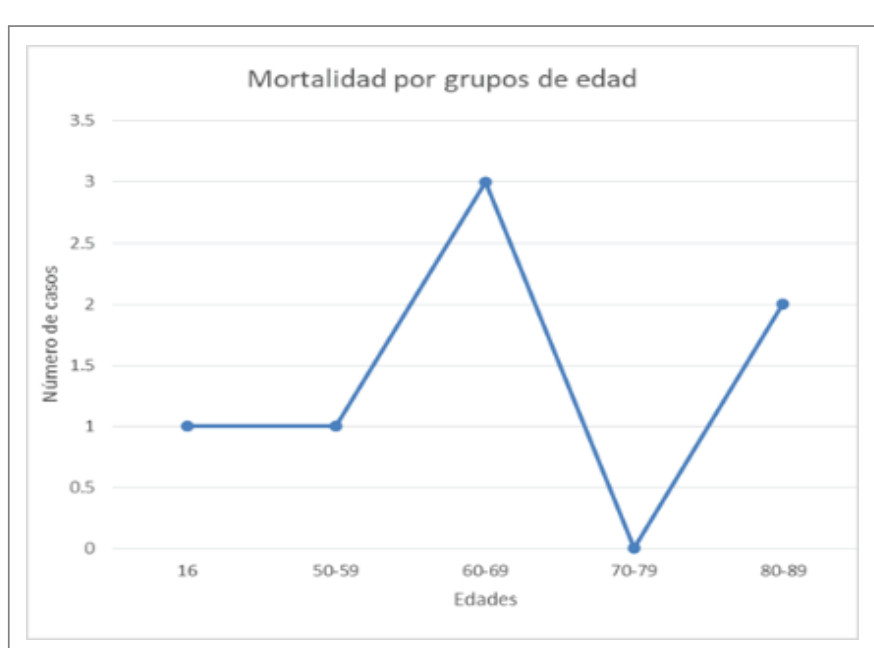

Graph 1: Mortality rates by age group (IMSS).

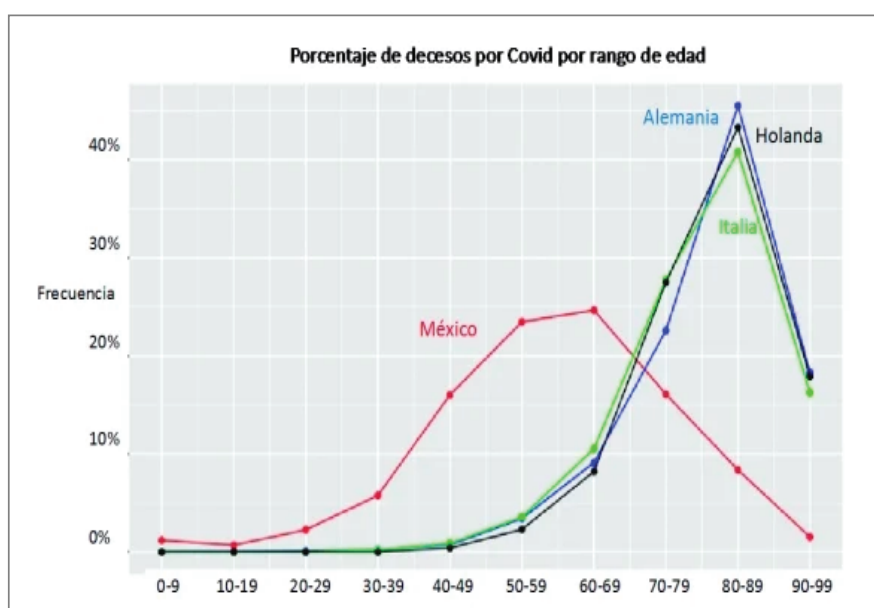

Graph 2: Mortality rate by age group on national scale.

of 62.5 in men. Reporting $45 \%$ mortality rate in $40-59$ years old group (Table 4).

There was a remarkably high mortality rate among patients with acute arterial disease in lower limbs.

Teaching received by the disease should be analyzed, taking into account the constant evolution in the knowledge about the disease. So far, low platelet counts have been shown as severity marker with mortality rates between 4 and $57 \%$. In a fourth of the patients a suboptimal DVT prophylaxis has also been reported, and 25\% of the patients with SARS COV 2 have revealed DVT, Cui S, et al. [13]. From 5 to $30 \%$ of the patients in ICU were detected with DVT at their arrival, meaning there is a direct relationship between vascular thrombosis and severe inflammation.

Lack of data about the disease has created fear and doubt among patients and health personnel, fact reflected in the morbidity and mortality rates during our study analysis. The pandemic background creates a tunnel vision; making and any other disease aside from COVID-19 seem secondary. All these, lead to delayed treatment in $37 \%$ of the patients, misdiagnosis in $37 \%$ of them and poor prioritization in medical treatment.

\section{Conclusions}

"Management strategies vary a lot among institutions and it is highly probable to keep changing as we learn more about this disease" [17].

We have a long road ahead of us before we can say we are fully ready to keep up with this new medical scenario. We should not forget that state of the art and high quality medicine practice must focus on prophylaxis and prevention of as many complications as we can foresee. A disease treatment only philosophy has to be considered obsolete so we have to see the big picture, create educational simulations and have backup plans to deal with the improbable, become anti fragile.

\section{References}

1. Pastrian-Soto G (2020) Bases Genéticas y Moleculares del COVID-19 (SARS-CoV-2). Mecanismos de Patogénesis y de Respuesta Inmune. Int J Odontostomat 14: 331-337.

2. Subsecretaria de Prevención y Promoción de la Salud. Gobierno de México. Informe técnico diario COVID-19 México.

3. Saltigeral-Simental P, León-Lara X (2020) Virus SARS-CoV-2 ¿Qué se sabe al momento? Acta Pediatr Méx: S3-S7.

4. Wrapp D, Wang N, Corbett KS, Goldsmith JA, Hsieh CL, et al. (2020) Cryo-EM structure of the 2019-nCoV spike in the prefusion conformation. Science 367: 1260-1263.

5. Wallentin L, Lindbäck J, Eriksson N, Hijazi Z, Eikelboom JW, et al. (2020) Angiotensin-converting enzyme 2 (ACE2) levels in relation to risk factors for COVID-19 in two large cohorts of patients with atrial fibrillation. Eur Heart J 41: 1-10.

6. Heurich A, Hofmann-Winkler H, Gierer S, Liepold T, Jahn O, et al. (2014) TMPRSS2 and ADAM17 cleave ACE2 differentially and only proteolysis by TMPRSS2 augments entry driven by the severe acute respiratory syndrome coronavirus spike protein. J Virol 88: 12931307.

7. Mucha SR, Dugar S, McCrae K, Douglas EJ, Bartholomew J, et al. (2020) Coagulopathy in COVID-19: Manifestations and management. CCJM 87: 461-468.

8. Cleveland Clinic. Coagulopatía asociada a COVID-19.

9. Klok FA, Kruip MJHA, van der Meer NJM, Arbous MS, Gommers DAMPJ, et al. (2020) Incidence of thrombotic complications in critically ill ICU patients with COVID-19. Thromb Res 191: 145-147.

10. Beccara LA, Pacioni C, Ponton S, Francavilla S, Cuzzoli A (2020) Arterial Mesenteric Thrombosis as a Complication of SARS-CoV-2 Infection. EJCRIM 7: 001690.

11. Mestres G, Puigmacià R, Blanco $C$, Yugueros X, Esturrica M, et al. (2020) Risk of peripheral arterial thrombosis in COVID-19. J Vasc Surg 72: 756-757.

12. Bilaloglu S, Aphinyanaphongs $Y$, Jones $S$, Iturrate $E$, Hochman J, et al. (2020) Thrombosis in Hospitalized Patients With COVID-19 in a New York City Health System. JAMA 324:799-801.

13. Cui S, Chen S, Li X, Liu S, Wang F (2020) Prevalence of venous thromboembolism in patients with severe novel coronavirus pneumonia. J Thromb Haemost 18: 1421-1424.

14. Washington Post (2020) A blood complication is killing COVID-19 patients. Ariana EunjungCha.

15. Costa Rica (2020) Some studies of Coagulopathy associated with COVID-19. 
16. Cristopher D (1983) Tratado de Patología Quirúrgica. La Habana: Editorial Científico-Técnica 1: 1033.

17. Katkhouda N, Mason RJ, Towfigh S, Gevorgyan A, Essani R (2005) Laparoscopic versus open appendectomy: a prospective randomized double-blind study. Ann Surg 242: 439-450.

18. Bahena-Aponte JA, Chávez-Tapia NC, Méndez-Sánchez N (2003) Estado actual de la apendicitis. Médica Sur México 10: 122-128.

19. González HMR, Yáñez IEP, Fajardo RCS, Hernández JEM, Chávez NAM (2014) Prevalence of Acute Appendicitis in a Second Level Care Center. Cir Gen 36:87-90.

20. Beltrán MA (2012) Right hemicolectomy in patients operated on for appendicitis: from McBurney's incision and appendectomy, tomidlinelaparotomy and hemicolectomy. Rev Colomb Cir 27: 129138.
21. Bizueto-Rosas H, Hernández-Pérez NA, Jaime-Gámiz G (2002) Morbilidad y mortalidad en la cirugía de urgencia de la colecistitis crónica litiásica agudizada. Cir Cir 70: 82-85.

22. Santamaría AJR, Rodríguez WU, Sámano GM, Caballero AG (2009) Gallbladder perforation secondary to hydrocholecyst and severe sepsis of biliary origin. Case report and literature review. Rev Hosp Jua Mex 76: 40-43.

23. Casillas JA, Arcas R, De La Fuente A, Trenor AM, Llorens R, et al. (1979) Embolectomía arterial en extremidades Resultados en 66 casos. Angiología XXXI 6: 250-254.

24. Prada KJP, Hernández RAP, Tamayo CNT (2017) Late embolectomy in acute lowerlimb ischemia. Rev Cub Angiol Cir Vasc 18: 208-217.

25. García RV, Tamayo CNT, Martínez YTG, Pacheco JB, González MEM (2017) Clinical and epidemiological characteristics of the patients amputated in the General Hospital of Ciego de Ávila. Mediciego 23. 